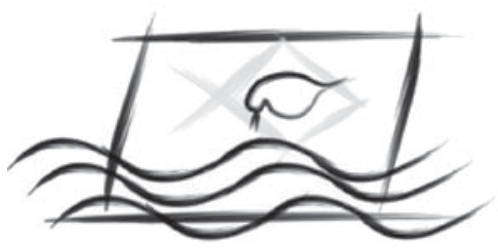

J. Braz. Soc. Ecotoxicol., v. 4, n. 1-3, 2009, 1-7

doi: 10.5132/jbse.2009.01.001

ECOTOX - Brazil

\title{
Determinação da Ecotoxicidade Crônica para Danio rerio
}

\author{
E. Bertoletti \\ Setor de Ecotoxicologia Aquática \\ Companhia Ambiental do Estado de São Paulo - CETESB, São Paulo, Brasil
}

(Received August 14, 2008; Accepted July 27, 2009)

\begin{abstract}
RESUMO
Embora os peixes Danio rerio e Pimephales promelas pertençam à família dos ciprinídeos os métodos de ensaio ecotoxicológico originalmente desenvolvidos, para ambas as espécies, possuem diferenças experimentais que dificultam a comparação dos resultados analíticos. Com a finalidade de verificar a equivalência na intensidade do efeito tóxico para essas espécies de peixe, foram efetuados ensaios com Danio rerio utilizando 10 agentes químicos nas mesmas condições experimentais do ensaio com Pimephales promelas. Nessas condições, foi demonstrado que o cálculo do Valor Crônico estimado (VCest) para Danio rerio, isto é, a multiplicação da CL(I) $15 ; 168 \mathrm{~h}$ pelo fator 0,3 , gera valores equivalentes aos ensaios crônicos de duração $\geq 28$ dias com Pimephales promelas. Os resultados desse trabalho subsidiaram a normalização, pela ABNT (Associação Brasileira de Normas Técnicas), do ensaio para avaliar os efeitos tóxicos crônicos para peixes.
\end{abstract}

Palavras-chave: correlação, Danio rerio, ensaio crônico, peixe, Pimephales promelas.

\section{ABSTRACT}

\section{Determination of chronic ecotoxicity to Danio rerio}

Although the fishes Danio rerio and Pimephales promelas belong to the family Cyprinidae, the original methods described for ecotoxicological assay using these species have experimental differences, which cause some problems when results are compared. In order to verify the equivalence of toxic effects for these fish species, assays with Danio rerio were performed using 10 chemicals under the same experimental conditions described for Pimephales promelas assay. In such conditions it was demonstrated that the calculated CVest (estimated chronic value) to Danio rerio, or 168h-LC15 multiplied by 0.3 factor, generates equivalent values to $\geq 28$ days chronic assays with Pimephales promelas. The results of this paper were the basis for the ABNT (Associação Brasileira de Normas Técnicas) assay standardization to evaluate toxic chronic effects to fish.

Keywords: correlation, chronic assay, Danio rerio, fish, Pimephales promelas.

\section{INTRODUÇÃO}

Atualmente, os ensaios ecotoxicológicos com organismos aquáticos são requeridos por diversos instrumentos legais voltados à proteção da biota em corpos hídricos brasileiros, conforme demonstrado por Bertoletti, Zagatto (2008). Apesar da crescente demanda dos ensaios ecotoxicológicos Aragão, Araújo (2008) citam que, no Brasil, apenas o método de ensaio ABNT-NBR 15499 (ABNT, 2007) é destinado à avaliação dos efeitos crônicos para peixes.

Nesse método padronizado são utilizadas duas espécies de peixe, Danio rerio (paulistinha) e Pimephales promelas ("fathead minnow"), as quais se mostram apropriadas para o método de ensaio crônico visto que podem se reproduzir continuamente em condições de laboratório. Considerando que essas duas espécies são mencionadas para o mesmo método de ensaio poder-se-ia supor que as mesmas possuem a mesma sensibilidade. No entanto, a consulta à literatura especializada demonstra que há uma carência de dados comparativos para confirmar essa suposição, em termos dos efeitos tóxicos crônicos, principalmente em ensaios de curta duração. Em estudo com cobre, fenol e pentaclorofenol, Meinelt, Staaks (1994) compararam a sensibilidade de ambas as espécies, porém algumas condições experimentais (tempo de exposição, alimentação e dureza da água) não foram equivalentes.

* Corresponding author: Eduardo Bertoletti, e-mail: ebertoletti@terra.com.br 
Comparações apropriadas, entre as duas espécies de peixe, somente são registradas no estudo de Nagel et al. (1991) com 3,4-dicloroanilina e naquele efetuado por Elonen et al. (1998) com 2,3,7,8-tetraclorodibenzo-p-dioxina, sendo que nesses estudos o Danio rerio mostrou-se menos sensível do que o Pimephales promelas.

Analisando os métodos analíticos originais, desenvolvidos para estimar os efeitos crônicos de curta duração com cada uma dessas espécies de peixes, é possível justificar as dificuldades nas comparações da sensibilidade. Segundo a OECD (1998) o ensaio com Danio rerio (Dave et al., 1987) não possui duração pré-definida, podendo se estender por 12 a 15 dias quando as larvas morrem por inanição, enquanto no ensaio com Pimephales promelas (Norberg; Mount, 1985) há uma duração pré-determinada, de sete dias. Esta diferença na duração do ensaio pode resultar em diferentes respostas das espécies em questão e comparações duvidosas, uma vez que a ecotoxicidade de um agente químico é também função do tempo de exposição.

Além disso, os ensaios citados se iniciam em fases distintas do ciclo vital, isto é, enquanto a exposição do Danio rerio se inicia na fase embrionária a do Pimephales promelas começa na fase larval. Este aspecto interfere na intensidade do efeito tóxico, conforme demonstrado por Leland, Kuwabara (1985) e Norberg-King (1989), que apontaram a maior resistência dos embriões de diferentes espécies de peixes aos metais (mercúrio, chumbo, cobre, cádmio e zinco) devido ao decréscimo da permeabilidade dos ovos após o estágio de blástula. Assim, em função do Danio rerio se encontrar na fase embrionária no início dos experimentos, é naturalmente esperado que esse peixe se mostre mais resistente aos agentes químicos.

Em função dos aspectos mencionados, o presente estudo aborda os resultados de ensaios crônicos de curta duração com o Danio rerio, utilizando 10 agentes químicos, efetuados nas mesmas condições experimentais do ensaio com Pimephales promelas, o qual possui uma ampla base de resultados de ensaios crônicos. Desse modo, esse estudo fornece informações mais precisas sobre a sensibilidade relativa dessas duas espécies de peixes, com o intuito de justificar a inclusão do peixe Danio rerio no método de ensaio crônico padronizado pela ABNT (2007).

\section{MATERIAL E MÉTODOS}

O método de ensaio, bem como as condições de cultivo, seguiu o descrito na norma ABNT-NBR 15499 (ABNT, 2007). Resumidamente, os ensaios foram efetuados em sistema semi-estático (com renovação diária das soluções-teste, exceto aos sábados e domingos), utilizando-se três ou quatro replicatas (com volume de 250,0 mL) para cada solução-teste (máximo de 5), sendo adicionados 10 organismos em cada uma das replicatas. O tempo de exposição dos organismos foi de 168 horas, sendo a letalidade o efeito observado. Nos ensaios ecotoxicológicos foram utilizadas larvas recém-eclodidas, com menos de 24 horas, da espécie de peixe Danio rerio [Hamilton-Buchanan,1822], as quais não receberam qualquer tipo de alimento. As larvas foram provenientes do cultivo efetuado no laboratório do Setor de Ecotoxicologia Aquática-CETESB (Companhia Ambiental do Estado de São Paulo), sendo que esses organismos foram provenientes de lotes de ovos com mortalidade $\leq 33 \%$, conforme recomendado por Dave et al. (1987).
A água utilizada, tanto na manutenção e cultivo dos organismos como nos ensaios ecotoxicológicos, foi a da rede de abastecimento após descloração (por meio de aeração intensa). A medição do cloro livre remanescente, na água utilizada, foi efetuada com o kit "Microquant" da Merck ${ }^{\circledR}$. As características físicas e químicas da água de diluição são apresentadas na Tabela 1 .

As seguintes substâncias foram utilizadas nos ensaios ecotoxicológicos: cloreto de cádmio $\left(\mathrm{CdCl}_{2} 21 / 2 \mathrm{H}_{2} \mathrm{O}\right)$, da Baker Analyzed $^{\circledR}$; sulfato de cobre $\left(\mathrm{CuSO}_{4} 5 \mathrm{H}_{2} \mathrm{O}\right)$, da Merck ${ }^{\circledR}$; dicromato de potássio $\left(\mathrm{K}_{2} \mathrm{Cr}_{2} \mathrm{O}_{7}\right)$, da Merck ${ }^{\circledR}$; sulfato de níquel $\left(\mathrm{NiSO}_{4} 6 \mathrm{H}_{2} 0\right)$, da CAAL ${ }^{\circledR}$; cloreto de mercúrio $\left(\mathrm{HgCl}_{2}\right)$, da Merck $^{\circledR}$; nitrato de prata $\left(\mathrm{AgNO}_{3}\right)$, da Química Moderna ${ }^{\circledR}$; sulfato de zinco $\left(\mathrm{ZnSO}_{4} 7 \mathrm{H}_{2} \mathrm{O}\right)$, da Carlo Erba ${ }^{\circledR}$; fenol, da Synth $^{\circledR}$; cloreto de sódio $(\mathrm{NaCl})$, da Merck ${ }^{\circledR}$; cloreto de amônio $\left(\mathrm{NH}_{4} \mathrm{Cl}\right)$, da Merck ${ }^{\circledR}$. Ao longo do trabalho os sais metálicos foram expressos em massa nominal do metal estudado. Os teores de amônia não ionizada foram calculados com base na concentração nominal de nitrogênio amoniacal, segundo a Equação 1 abaixo estabelecida por Emerson et al. (1975):

$$
\text { porcentagem de amônia não ionizada }=\frac{1}{\left(10^{p K a-p H}+1\right)}
$$

em que:

$\mathrm{pKa}=$ constante de ionização em função da temperatura da solução (tabelada);

pH = potencial hidrogeniônico da solução (medido).

Os resultados dos ensaios foram expressos em CL(I) $15 ; 168 \mathrm{~h}$ (concentração nominal do agente químico que causa letalidade a 15\% das larvas, em 168 horas de exposição). Para o cálculo da CL(I)15;168h foi utilizado o método computadorizado Inhibition Concentration (Norberg-King, 1993). O valor crônico estimado (VCest;168h), isto é, concentração nominal do agente químico que não causa efeito expressivo na sobrevivência e crescimento de larvas, em 168 horas de exposição, foi calculado multiplicando-se o fator 0,3 pela $\mathrm{CL}(\mathrm{I}) 15 ; 168 \mathrm{~h}$.

A análise de regressão, usada para correlacionar os resultados dos ensaios com Danio rerio e Pimephales promelas, foi efetuada pelo método dos mínimos quadrados utilizando-se o programa computadorizado Microcal Origin, versão 4.1, 16 bit (Northampton, MA/USA). De acordo com os diagramas de dispersão, foi utilizada a função não-linear redutível à forma linear, como segue:

\section{$\log y=a+b \log x$}

em que:

$\mathrm{y}=$ resultado do ensaio de ecotoxicidade com Danio rerio (D.r.);

Tabela 1 - Características da água de diluição utilizada nos ensaios

\begin{tabular}{lrc}
\hline \multicolumn{1}{c}{ Variável } & Média & Amplitude \\
\hline Temperatura $\left(\mathrm{em}^{\circ} \mathrm{C}\right)$ & 24,5 & $23,0-27,5$ \\
$\mathrm{pH}(\mathrm{em}$ unidades $)$ & 7,5 & $6,3-8,0$ \\
Oxigênio dissolvido $\left(\mathrm{em} \mathrm{mg} \mathrm{O}_{2} \mathrm{~L}^{-1}\right)$ & 6,9 & $6,1-7,5$ \\
Dureza total $\left(\mathrm{em} \mathrm{mg} \mathrm{CaCO}_{3} \mathrm{~L}^{-1}\right)$ & 45,3 & $35,0-62,0$ \\
Condutividade $\left({\left.\mathrm{em} \mu \mathrm{Sm}^{-1}\right)}^{1}\right)$ & 156,0 & $108,0-255,0$ \\
\hline
\end{tabular}


$\mathrm{x}=$ resultado do ensaio de ecotoxicidade com Pimephales promelas (P.p.);

$\mathrm{a}=$ intersecção com o eixo $\mathrm{y}$;

$b=$ coeficiente angular da regressão.

O erro padrão corrigido para a equação de regressão, denominado limite de previsão (LP) $95 \%$ (Equação 2), foi calculado como segue:

$$
L P=10^{t \cdot s}[1+1 / \mathrm{N}]^{1 / 2}
$$

em que:

$\mathrm{t}=0,95$ da distribuição de Student, com n-2 graus de liberdade $(2,306)$;

$\mathrm{S}=$ desvio padrão do resíduo $(0,4513)$;

$\mathrm{N}=$ número de pares de dados (10).

\section{RESULTADOS E DISCUSSÃO}

Com a finalidade de estabelecer qualquer método ecotoxicológico, é imprescindível o uso de agentes químicos diferenciados. Idealmente, tais agentes devem ter sido ensaiados com métodos desenvolvidos para outras espécies de organismos e, além disso, possuírem características toxicológicas peculiares. Assim, somente com uma maior diversidade de substâncias, é possível efetuar comparações que validem tanto o método como a sensibilidade do organismo estudado. Considerando esses aspectos, no presente trabalho foram utilizados dez agentes químicos para os ensaios com Danio rerio, sendo que os resultados analíticos foram comparados àqueles gerados com o Pimephales promelas.

Os resultados dos ensaios de letalidade com larvas de Danio rerio, expressos em CL(I) $15 ; 168 \mathrm{~h}$, são apresentados na Tabela 2. A fase do ciclo vital utilizada para essa espécie assim como a expressão dos resultados se justificam, pois, de acordo com Bertoletti (2000), a fase larval do Danio rerio é significativamente mais sensível do que as fases embriolarval e juvenil, em experimentos com 96 e 168 horas de exposição. O autor também constatou que o uso da CL(I) $15 ; 168 \mathrm{~h}$, calculada pelo método de interpolação linear, permite a obtenção de resultados pouco variáveis e equivalentes ao método dos probitos, além de expressar uma boa precisão analítica.

A comparação dos resultados descritos na Tabela 2 permite verificar que, as médias das CL(I) $15 ; 168 \mathrm{~h}$ nos ensaios com Danio rerio apresentaram-se de duas (para o cobre) a 56 vezes (para o mercúrio) mais elevadas em relação aos Valores Crônicos (VC) dos ensaios de duração curta (168h) e prolongada ( $\geq 28$ dias) com Pimephales promelas. Em termos ecotoxicológicos, isso significa que, tomando o Pimephales promelas como espécie de referência, os ensaios com Danio rerio não seriam apropriados para estimar efeitos crônicos. Na prática, seria de se esperar que, para vários agentes químicos, concentrações abaixo das CL(I)15 para Danio rerio ainda causassem efeitos tóxicos significativos para Pimephales promelas.

Essas diferenças expressivas entre os resultados dos ensaios com Danio rerio e Pimephales promelas seriam previsíveis, visto que o tempo de exposição é bastante diferenciado (sete e $\geq 28$ dias, respectivamente), mas não seriam esperadas se considerarmos o tempo de exposição de 168 horas. Entretanto, conforme demonstrado na Tabela 2, as pesquisas originais indicam que nos ensaios de curta duração (168h) os efeitos tóxicos são mais freqüentes sobre o crescimento das larvas do Pimephales promelas, enquanto esses efeitos são detectados com a mesma intensidade na sobrevivência juvenil desse peixe nos ensaios de duração prolongada ( $\geq 28$ dias). Esse fato foi utilizado por Norberg-King (1989) para justificar a utilização de ensaios de curta duração para esse peixe. Com base em algumas evidências científicas, Bertoletti (2000) supõe que essas respostas diferenciadas ocorram devido ao efeito tóxico temporário no crescimento larval do Pimephales promelas, isto é, efeito tóxico intenso durante a fase larval que é atenuado, ou inexpressivo, em fases posteriores do ciclo vital. Por tal motivo, considerando a conveniência do uso dos efeitos tóxicos no crescimento de Pimephales promelas nos ensaios de curta

Tabela 2 - Resultados dos ensaios com Danio rerio e comparações com os ensaios efetuados com Pimephales promelas, em águas com dureza total semelhante. (Expoentes indicam a fonte bibliográfica e o critério mais sensível para determinação do efeito tóxico).

\begin{tabular}{|c|c|c|c|c|c|}
\hline Agente químico & $\begin{array}{l}\mathrm{N}^{\circ} \text { de ensaios } \\
\text { com } \\
\text { Danio rerio }\end{array}$ & $\begin{array}{c}\text { Média das } \\
\text { CL(I) } 15 ; 168 \mathrm{~h} \text { para } \\
\text { larvas do Danio rerio }\end{array}$ & $\begin{array}{l}\text { VCest; } 168 \mathrm{~h}^{*} \\
\text { para larvas do } \\
\text { Danio rerio }\end{array}$ & $\begin{array}{c}\text { VC; } 168 \mathrm{~h}^{\star *} \\
\text { para larvas do } \\
\text { Pimephales promelas }\end{array}$ & $\begin{array}{c}\mathrm{VC} ; \geq 28 \mathrm{~d} \text { para } \\
\text { Pimephales promelas }^{* * *}\end{array}$ \\
\hline cádmio $\left(\mathrm{mg} \mathrm{L}^{-1}\right)$ & 4 & 0,054 & 0,016 & $0,016^{\mathrm{a}, \text { crescimento }}$ & $0,013^{\text {a, sobrevivência }}$ \\
\hline cobre $\left(\mathrm{mg} \mathrm{L}^{-1}\right)$ & 4 & 0,030 & 0,009 & $0,016^{\mathrm{k}, \text { crescimento }}$ & $0,014^{\text {b, sobrevivência }}$ \\
\hline $\operatorname{cromo}\left(\mathrm{mg} \mathrm{L}^{-1}\right)$ & 5 & 9,7 & 2,9 & $4,0^{\mathrm{a}, \text { crescimento }}$ & $2,0^{c, \text { sobrevivência }}$ \\
\hline níquel (mg L $\left.{ }^{-1}\right)$ & 4 & 5,9 & 1,8 & - & $0,22^{\mathrm{d}, \text { indeterminado }}$ \\
\hline mercúrio $\left(\mu \mathrm{g} \mathrm{L}^{-1}\right)$ & 5 & 40,0 & 12,0 & - & $0,71^{\text {e, crescimento }}$ \\
\hline prata $\left(\mu \mathrm{g} \mathrm{L}^{-1}\right)$ & 4 & 21,0 & 6,3 & $1,0^{\mathrm{a}, \text { crescimento }}$ & $0,49^{\mathrm{f}, \text { sobrevivência }}$ \\
\hline zinco $\left(\mathrm{mg} \mathrm{L}^{-1}\right)$ & 3 & 3,6 & 1,1 & $0,12^{\mathrm{k}, \text { sobrevivência }}$ & $0,21^{\mathrm{g} \text {, sobrevivência }}$ \\
\hline fenol $\left(\mathrm{mg} \mathrm{L}^{-1}\right)$ & 3 & 17,9 & 5,4 & - & $2,56^{\text {h, crescimento }}$ \\
\hline $\mathrm{NaCl}\left(\mathrm{g} \mathrm{L}^{-1}\right)$ & 5 & 2,0 & 0,6 & $0,71^{\mathrm{i}, \text { crescimento }}$ & - \\
\hline $\begin{array}{l}\text { amônia não } \\
\text { ionizada }\left(\mathrm{mg} \mathrm{L}^{-1}\right)\end{array}$ & 3 & 0,84 & 0,25 & - & $0,21^{\mathrm{j}, \text { sobrevivência }}$ \\
\hline
\end{tabular}

*VCest = Valor crônico estimado, isto é, valor da CL(I) $15 ; 168 \mathrm{~h} \times$ fator 0,3 ; ** VC = Valor crônico, isto é, média geométrica de CENO e CEO; e *** fonte: a) Norberg-King (1989); b) Mount, Stephan (1969); c) Pickering (1980); d) Lind et al., apud USEPA (1986); e) Snarski, Olson (1982); f) Holcombe et al. (1983); g) Benoit, Holcombe (1978); h) Holcombe et al. (1982); i) Norberg-King et al. (1991); j) Mayes et al. (1986); k) Norberg e Mount (1985). 
duração, parece razoável utilizar esse critério de avaliação nos experimentos com Danio rerio.

No entanto, a avaliação do efeito das substâncias no crescimento de Danio rerio é imprecisa, devido à sua reduzida capacidade de ingestão do alimento de origem externa na fase larval e, conseqüentemente, o crescimento inexpressivo desse organismo (dependente da reserva alimentar no saco vitelínico) no curto período dessa fase vital. Além disso, Dave, Xiu (1991) reforçam a dificuldade de medição do crescimento devido à ausência de alimento apropriado para o Danio rerio na fase larval. Por tais motivos é pertinente fazer extrapolações entre a letalidade e o crescimento do Danio rerio com base nas características de outro ciprinídeo, tal como Pimephales promelas.

Nesse sentido, com base em levantamento bibliográfico, Bertoletti (2000) obteve dados sobre a relação numérica entre a sobrevivência e o crescimento de Pimephales promelas e, também, de Danio rerio. Tais dados consistiram de 36 experimentos, com diferentes períodos de exposição e vários agentes químicos, onde exclusivamente a CENO (concentração de efeito não observado) para o crescimento foi menor que a CENO para a letalidade. Como resultado, notou-se que as concentrações que não causam efeito no crescimento foram, em média, três vezes menores do que aquelas que não afetam a sobrevivência. Ao mesmo tempo, observou-se que, da mesma forma que ocorreu para os ensaios com períodos de exposição mais prolongados, os ensaios com Pimephales promelas em sete dias de exposição mostraram razão igual a quatro. Ainda, merece destaque a razão média igual a 2,8 verificada nos poucos ensaios com Danio rerio (Görge; Nagel, 1990; VanLeeuwen et al., 1990), a qual indica a similaridade de respostas com o Pimephales promelas.

Portanto, levando-se em conta que, em ensaios crônicos de curta duração com ciprinídeos, os efeitos no crescimento podem prever efeitos em longo prazo, a razão três ou sua recíproca $(0,3)$ demonstra-se apropriada para extrapolar os efeitos no crescimento com base na sobrevivência de larvas do Danio rerio. Resultado idêntico (razão 0,3 ) foi obtido por Mayer et al. (1986), em estudo com sete espécies de peixes e 28 agentes químicos diferentes daqueles apresentados no presente trabalho. Na pesquisa de Mayer et al. (1986) foi também apontado que o fator 0,2 pode ser aplicado aos resultados de sobrevivência, em ensaios crônicos, com a finalidade de evitar outros efeitos tóxicos biologicamente significativos.

Assim, aplicando a razão 0,3 às CL(I) $15 ; 168$ h para larvas de Danio rerio (Tabela 2), verifica-se que os Valores Crônicos estimados (VCest; 168h) se aproximaram dos Valores Crônicos (VC) $168 \mathrm{~h}$ ou $\geq 28$ dias para Pimephales promelas. Para a maioria dos agentes químicos a diferença entre os $\mathrm{VC}$ foi menor que a razão 2, considerada em publicações de referência (McKim, 1977; Chapman, 1983; Norberg-King, 1989) como pouco expressiva, visto que corresponde à precisão analítica esperada em ensaios ecotoxicológicos. Já para outros agentes químicos essa razão foi maior, sendo o caso do níquel (razão 8), mercúrio (razão 17), prata (razão 13) e zinco (razão 5). A maior resistência de Danio rerio a esses metais pode ser natural dessa espécie, visto que nos ensaios de ecotoxicidade aguda Bertoletti (2000) constatou a mesma tendência para o níquel, prata e zinco. Quanto ao mercúrio, é suposto que a maior sensibilidade de Pimephales promelas esteja associada ao maior período de exposição dessa espécie, de 41 semanas, no estudo de Snarski e Olson (1982).

VanLeeuwen et al. (1990) afirmaram que, para agentes químicos que exercem efeitos tóxicos após ativação metabólica, os resultados dos ensaios de curta duração (168 horas) são inadequados para prever efeitos tóxicos na sobrevivência em ensaios de longa duração, devido ao fato de apresentarem-se ao redor de uma ordem de magnitude menos tóxicos. No entanto, aplicando-se a razão 0,3 aos resultados dos ensaios embriolarvais efetuados por VanLeeuwen et al. (1990), com Danio rerio e seis substâncias com modo de ação específico (anilina e cloroanilinas), verificou-se que a diferença na previsão do efeito crônico em 28 dias foi de, apenas, três vezes para cinco dos referidos agentes químicos. Essa diferença poderia ser ainda menor, praticamente inexistente, uma vez que os ensaios de VanLeeuwen et al. (1990) foram efetuados com a fase embriolarval de Danio rerio, a qual é ao redor de três vezes mais resistente do que a fase larval, segundo Bertoletti (2000). Portanto, esses dados também confirmam a adequação do uso do fator 0,3 na previsão dos efeitos em longo prazo, tendo com base os resultados de ensaios de curta duração com a sobrevivência do Danio rerio.

Na Figura 1 é apresentada a análise de regressão que consiste em outra forma de avaliar a adequação dos Valores Crônicos estimados (VCest;168h), nos ensaios com Danio rerio, com os Valores Crônicos (VC $\geq 28$ dias) dos ensaios com Pimephales promelas (Tabela 2). A preferência por utilizar os dados de VC $\geq 28 \mathrm{~d}$ na Figura 1, ao invés do VC; $168 \mathrm{~h}$ com larvas do Pimephales promelas, foi motivada pela maior quantidade de resultados analíticos. A Figura 1 mostra que, mesmo com as diferenças de sensibilidade apontadas para o níquel, mercúrio, prata e zinco, foi obtido um excelente coeficiente de determinação $\left(\mathrm{r}^{2}=0,93\right)$. Deve-se notar que os dados de $\mathrm{NaCl}$ com larvas de Pimephales promelas foram incluídos na análise, uma vez que inexistem estudos de longa duração com esse composto, sendo que sua exclusão reduziria pouco o coeficiente de determinação $\left(\mathrm{r}^{2}=0,86\right)$.

A pesquisa na literatura especializada indica que $o$ coeficiente obtido foi similar àqueles encontrados em outros estudos, embora tenham realizado análises de regressão com ensaios de ecotoxicidade aguda. Por exemplo, Kenaga (1978) e Doherty (1983) encontraram $\mathrm{r}^{2}=0,92 \mathrm{e} \mathrm{r}^{2}=0,95$, respectivamente, com os peixes Lepomis macrochirus ("bluegill") e Pimephales promelas em ensaios com nove substâncias. Dados retrabalhados do estudo de Mayer, Ellersieck (1986) mostram correlações expressivas entre Pimephales promelas com os ciprinídeos Carassius auratus $\left(\mathrm{r}^{2}=0,94\right)$ e Cyprinus carpio $\left(\mathrm{r}^{2}=0,92\right)$, além de Perca flavescens $\left(\mathrm{r}^{2}=0,98\right)$, em ensaios com sete a 19 agentes químicos.

Apesar da excelente correlação obtida, é pertinente a validação da equação apresentada na Figura 1. Nesse sentido, foram selecionados quatro agentes químicos, para os quais estavam disponíveis resultados de ecotoxicidade crônica tanto para Danio rerio como para Pimephales promelas (Tabela 3). Torna-se importante notar que as substâncias usadas nessa 


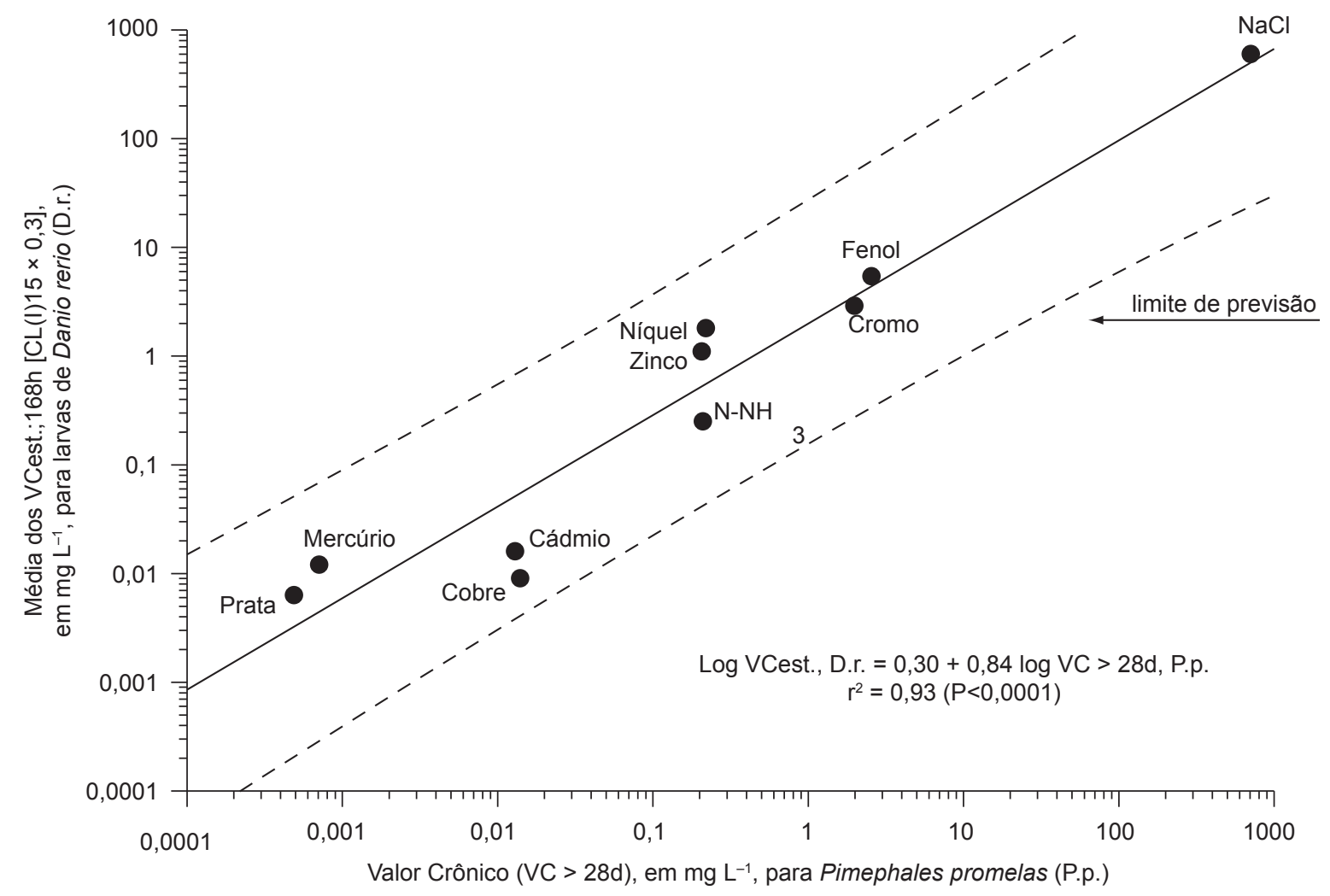

Figura 1 - Equação, reta e limites de previsão $95 \%$, da análise de regressão para os resultados dos ensaios crônicos com Danio rerio (em VCest) e Pimephales promelas (em VC).

Tabela 3 - Validação da equação estabelecida para estimar o efeito tóxico a larvas do Danio rerio com base nos ensaios de duração prolongada com Pimephales promelas.

\begin{tabular}{|c|c|c|c|}
\hline \multirow[b]{2}{*}{ Agente químico } & \multicolumn{2}{|c|}{$\mathrm{CENO} \geq 28$ dias determinada experimentalmente } & \multirow{2}{*}{$\begin{array}{c}\text { CENO } \geq 28 \text { dias estimada para } \\
\text { larvas do Danio rerio }{ }^{* *}\end{array}$} \\
\hline & Pimephales promelas & Danio rerio & \\
\hline 3,4-dicloroanilina $\left(\mathrm{em} \mu \mathrm{g} \mathrm{L}^{-1}\right)$ & $5,1^{\mathrm{a}}$ & $20,0^{\mathrm{b}}$ & 7,8 \\
\hline lindano $\left(e m \mu g L^{-1}\right)$ & $>23,4^{c}$ & $40,0^{\mathrm{d}}$ & $>28,2$ \\
\hline atrazina $\left(e m \mu \mathrm{g} \mathrm{L}^{-1}\right)$ & $>213,0^{\mathrm{e}}$ & $300,0^{\mathrm{d}}$ & $>180,2$ \\
\hline diazinon $\left(e m \mathrm{mg} \mathrm{L}^{-1}\right)$ & $0,05^{\mathrm{f}}$ & $>0,20^{\mathrm{g}}$ & 0,24 \\
\hline
\end{tabular}

*Fonte: a) Call et al. (1987); b) Nagel et al. (1991); c) Macek et al. (1976, apud Görge, Nagel (1990)); d) Görge, Nagel (1990); e) Macek et al. (1976b), apud Görge, Nagel (1990)); f) Jarvinen, Turner (1982); g) Bresch (1991); e **estimativa pela equação: log VCest, Danio rerio = 0,30 + 0,84 log VC, Pimephales promelas.

validação pertencem a grupos químicos diferentes daqueles que deram origem à equação de regressão. Como resultado, na Tabela 3, verifica-se que as estimativas de efeito crônico não observado (CENO) para Danio rerio foram muito próximas àquelas determinadas experimentalmente. À exceção da 3,4 dicloroanilina, a diferença entre os valores de CENO determinados e estimados foi menor que a razão 2 , indicando assim a pertinência da equação estabelecida. Desse modo, é possível constatar que os valores de VCest; $168 \mathrm{~h}$ são apropriados para estimar o efeito tóxico em períodos de exposição mais prolongados.

Tão importante quanto o coeficiente de determinação e a equação determinada são os limites de previsão a $95 \%$. Estatisticamente, os limites de previsão são análogos aos de confiança. Enquanto os limites de confiança são restritos ao conjunto de dados utilizados na equação, os limites de previsão são aqueles dentro dos quais se espera que se localizem $95 \%$ das observações futuras e independentes (Draper; Smith, 1981). Alguns pesquisadores (Kenaga, 1978; Doherty, 1983; e Sloof et al., 1986) utilizaram esses limites para a seleção de organismos aquáticos que representassem outros em ensaios de ecotoxicidade aguda.

Na Figura 1 está representado o limite de previsão 95\% entre os resultados do VCest $; 168 \mathrm{~h}$ com Danio rerio e do $\mathrm{VC} \geq 28$ dias com Pimephales promelas. Numericamente, esses limites foram de $\pm 11,5$ vezes, o que representa $\pm 1,15 \mathrm{em}$ ordem de magnitude. Deste modo, com uma probabilidade de $95 \%$, os valores estimados de ecotoxicidade crônica para Danio rerio podem corresponder até 11,5 vezes os valores determinados, analiticamente, para Pimephales promelas. Em termos reais, a Tabela 3 demonstra que os valores estimados para Danio rerio foram, no máximo, 4,8 vezes maiores do 
que aquele determinado para o Pimephales promelas, porém essas estimativas foram similares aos resultados obtidos experimentalmente com Danio rerio. Os limites de previsão representados na Figura 1 são muito semelhantes aos obtidos, por outros autores, em ensaios de ecotoxicidade aguda. Em estudo desenvolvido por Kenaga (1978) foram obtidos limites de previsão que variaram de $\pm 0,91$ a 1,42 ordens de magnitude das CL50, para correlações entre as espécies Salmo gairdneri, Lepomis macrochirus e Pimephales promelas. O cálculo dos dados disponibilizados na pesquisa de Doherty (1983) permite verificar um limite de previsão de \pm 1,6 ordem de magnitude para a equação de regressão, com as espécies de peixe Salmo gairdneri e Lepomis macrochirus, consideradas pelo autor como as únicas de sensibilidade equivalente em termos de ecotoxicidade aguda.

Com base nos resultados apresentados (Tabela 2) e na correlação obtida (Figura 1), verifica-se que o VCest;168h é apropriado para estimar os efeito tóxico crônico de substâncias e efluentes líquidos. No caso de efluentes, poder-se-ia supor dificuldades de determinar a VCest;168h para os despejos que não apresentam efeitos significativos na sobrevivência do Danio rerio. No entanto, a experiência com esse tipo de despejos permite constatar que é possível calcular a CL(I)15, mesmo com baixas porcentagens de letalidade na solução-teste mais concentrada ( $100 \%$ do efluente), ainda que essa letalidade não seja significativa em relação ao controle experimental. Desse modo, com o cálculo da CL(I)15, e a posterior aplicação do fator 0,3 , garante-se a estimativa do eventual efeito crônico do efluente líquido para o Danio rerio.

Ainda, particularmente para efluentes, é necessário considerar a magnitude da ausência de efeito na sobrevivência em relação ao crescimento dos peixes. Nesse sentido, levantamento de resultados analíticos demonstrou que, nos ensaios efetuados com Pimephales promelas pelo laboratório brasileiro Bioensaios Ltda., quando há ausência de efeito tóxico na sobrevivência cerca de $45 \%$ dos resultados $(n=18)$ apontam $\mathrm{CENO}=50 \%$ para o crescimento (Elisangela P. Bender, comunicação pessoal). Desse modo, é possível verificar que, para uma porção expressiva de resultados, a CENO para o crescimento está bem próxima daquela para a letalidade $(\mathrm{CENO}=100 \%)$, ou seja, não mais que a razão 2 usualmente aceita como variação natural para qualquer método de ensaio ecotoxicológico.

Conforme demonstrado o nível de efeito (letalidade) igual a 15\% é apropriado para estimar efeitos crônicos em ensaios de curta duração com Danio rerio. Assim, o percentual complementar desse nível de efeito pode ser utilizado em teste de hipóteses com bioequivalência, o qual é uma alternativa recomendada para o cálculo de resultados de ensaios crônicos (Buratini; Bertoletti, 2008). Nesse contexto, Bertoletti et al. (2007) indicam o uso do percentual $=0,84$ para a constante de proporcionalidade em ensaios com a letalidade larval do Danio rerio.

Torna-se importante destacar que o método de ensaio apresentado nesse artigo não se limita à avaliação de substâncias e efluentes, podendo ser utilizado para caracterizar os efeitos crônicos em águas superficiais. Alguns estudos (Adams et al., 1983; Birge et al., 1989 e Waller et al.,1996) demonstraram que os ensaios com a letalidade das larvas de Pimephales promelas, efetuados em laboratório, fornecem estimativas confiáveis dos efeitos tóxicos observados em ambientes naturais. Nos referidos estudos foi possível observar, também, que a letalidade larval apresentou boas correlações $(r>0,92)$ com os efeitos adversos em comunidades naturais (expressos pela riqueza de peixes, riqueza e diversidade de macroinvertebrados bentônicos). Portanto, como base os argumentos apresentados, as condições experimentais propostas para o ensaio com Danio rerio, bem como a forma de expressão do resultado, podem fornecer estimativas fidedignas de efeito tóxico crônico para essa espécie de peixe.

\section{REFERÊNCIAS BIBLIOGRÁFICAS}

ABNT (Associação Brasileira de Normas Técnicas), 2007. Ecotoxicologia aquática - Toxicidade crônica de curta duraçãométodo de ensaio com peixes. Norma ABNT-NBR 15499. Rio de Janeiro. 21p.

ADAMS, W.J.; KIMERLE, R.A.; HEIDOLPH, B.B. \& MICHAEL, P.R., 1983. Field comparison of laboratory-derived acute and chronic toxicity data. In: Bishop, W.E.; Cardwell, R.D.; Heidolph, B.B. (Eds). Aquatic Toxicology and Hazard Assessment: Sixth Symposium. STP 802. Philadelphia. ASTM. p. 367-385.

ARAGÃO, M.A. \& ARAÚJO, R.P.A., 2008. Métodos de ensaios de toxicidade com organismos aquáticos. In: Zagatto, P.A. \& Bertoletti, E. (eds), Ecotoxicologia aquática: Princípios e aplicações. São Carlos. RIMA Ed., pp. 117-152.

BENOIT, D.A. \& HOLCOMBE, G.W., 1978. Toxic effects of zinc on fathead minnows Pimephales promelas in soft water. J.Fish. Biol. 13: 701-708.

BERTOLETTI, E. \& ZAGATTO, P.A. 2008. Aplicação dos ensaios ecotoxicológicos e legislação pertinente. In: Zagatto, P.A. \& Bertoletti, E. (eds), Ecotoxicologia aquática: Princípios e aplicações. São Carlos. RIMA Ed., pp. 347-382.

BERTOLETTI, E., 2000. Estimativa de efeitos tóxicos crônicos com Danio rerio (Pisces, Cyprinidae). [Tese de doutorado. Faculdade de Saúde Pública da USP]. 118p.

BERTOLETTI, E.; BURATINI, S.V.; PRÓSPERI, V.A.; ARAÚJO, R.P.A. \& WERNER, L.I., 2007. Selection of relevant effect levels for using bioequivalence hypothesis testing. J.Bras.Soc. Ecotoxicol. 2 (2):139-145.

BIRGE, W.J.; BLACK, J.A.; SHORT, T.M. \& WESTERMAN, A.G., 1989. A comparative ecological and toxicological investigation of a secundary wastewater treatment plant effluent and its receiving stream. Environ.Toxicol.Chem. $8:$ 437-450.

BRESCH, H., 1991. Early life-stage test in zebrafish versus a growth test in rainbow trout to evaluate toxic effects. Bull. Environ. Contam. Toxicol. 46 : 641-648.

BURATINI, S.V. \& BERTOLETTI, E., 2008. Análise estatística. In: Zagatto, P.A. \& Bertoletti, E. (Eds), Ecotoxicologia aquática: Princípios e aplicações. São Carlos. RIMA Ed., pp. 221-249.

CALL, D.J.; POIRIER, S.H.; KNUTH, M.L.; HARTING, S.L. \& LINDBERG, C.A., 1987. Toxicity fo 3,4-dichloroaniline in acute and early life-stage exposures. Bull. Environ. Contam. Toxicol. 38: 352-358.

CHAPMAN, G. A. 1983. Do organisms in laboratory tests respond like organisms in nature? In: Bishop, W.E.; Cardwell, R.D.; Heidolph, B.B. (Eds). Aquatic Toxicology and Hazard Assessment: Sixth Symposium. STP 802. Philadelphia, ASTM., p. 315-327. 
DAVE, G.; DAMGAARD, B.; GRANDE, M.; MARTELIN, J.E.; ROSANDER, B. \& VIKTOR, T., 1987. Ring test of an embryolarval toxicity test with zebrafish (Brachydanio rerio) using chromium and zinc as toxicants. Environ.Toxicol.Chem. $6: 61$ 71.

DAVE, G. \& XIU, R., 1991. Toxicity of mercury, copper, nickel, lead, and cobalt to embryos and larvae of zebrafish Brachydanio rerio. Arch.Environ. Contam. Toxicol. 21: 126-134.

DOHERTY, F.G., 1983. Interspecies correlations of acute aquatic median lethal concentration for four standard testing species. Environ.Sci.Tech. 17 (11): 661-665.

DRAPER, N.R. \& SMITH, H., 1981. Applied regression analysis. New York. John Wiley \& Sons, Inc. Second edition, 709 p.

ELONEN, G.E.; SPEHAR, R.L.; HOLCOMBE, G.W.; JOHNSON, R.D.; FERNANDEZ, J.D.; ERICKSON, R. J. \& TIETGE, J.E.; COOK, P.M., 1998. Comparative toxicity of 2,37,8-tetrachlorodibenzo-p-dioxin to seven freshwater fish species during early life-stage development. Environ.Toxicol. Chem. 17: 472-483.

EMERSON, K,; RUSSO, R.C.; LUND, R.E. \& THURSTON, R.V., 1975. Aqueous ammonia equilibrium calculations: effect of $\mathrm{pH}$ and temperature. J.Fish.Res.Board Can. 32 : 2379-2383.

GÖRGE, G. \& NAGEL, R., 1990. Toxicity of lindane, atrazine, and deltamethrin to early life stages of zebrafish (Brachydanio rerio). Ecotox.Environm.Safety. 20: 246-255.

HOLCOMBE, G.W.; PHIPPS, G.L. \& FIANDT, J.T., 1982. Effects of phenol, 2,4-dimethylphenol, 2,4-dichlorophenol, and pentachlorophenol on embryo, larval, and early-juvenile fathead minnow (Pimephales promelas). Arch.Environm.Contam. Toxicol. 11: 73-78.

HOLCOMBE, G.W.; PHIPPS, G.L. \& FIANDT, J.T., 1983. Toxicity of selected priority pollutants to various aquatic organisms. Ecotox.Environ.Safety, 7: 400-409.

JARVINEN, A. W. \& TANNER, D.K., 1982. Toxicity of selected controlled release and corresponding unformulated technical grade pesticides to the fathead minnows. Envir. Pollut. (Series A). $27: 179-195$.

KENAGA, E.E., 1978. Test organisms and methods useful for early assessment of acute toxicity of chemicals. Envir.Sci.Tech. 12 (12): 1322-1329.

LELAND, H.V. \& KUWABARA, J.S., 1985. Trace metals. In: Rand, G.M. \& Petrocelli, S.R. (Eds). Fundamentals of aquatic toxicology. Washington. Hemisphere Publ. p. $374-415$.

MAYER, F.L. \& ELLERSIECK, M.R., 1986. Manual of acute toxicity: interpretation and data base for 410 chemicals and 66 species of freshwater animal. Washington, U.S.Fish and Wildlife Service. Resource Publication 160, 579p.

MAYER, F.L.; MAYER, K.S. \& ELLERSIECK, M.R., 1986. Relation of survival to other endpoints in chronic toxicity tests with fish. Environ.Toxicol.Chem. 5 : 737-748.

MAYES, M.A.; ALEXANDER, H.C.; HOPKINS, D.L. \& LATVAITIS, P.B., 1986. Acute and chronic toxicity of ammonia to freshwater fish: a site-specific study. Environ.Toxicol.Chem. 5: 437-442.
McKIM, J.M. 1977. Evaluation of tests with early life stages of fish for predicting long-term toxicity. J. Fish. Res. Board Can. 34: 1148-1154.

MEINELT, T. \& STAAKS, G., 1994. The embryo-larval test with zebrafish (Brachydanio rerio): validity, limits and perspectives. In: Muller, R. e Lloyd, R. (eds). Sublethal and chronic effects of pollutants on freshwater fish. Oxford, FAO/FIsh.News Books. p: 167-174.

MOUNT, D.I. \& STEPHAN, C.E., 1969. Chronic toxicity of copper to the fathead minnow (Pimephales promelas) in soft water. J.Fish.Res.Bd.Canada 26: 2449-2457.

NAGEL, R.; BRESCH, H.; CASPERS, N.; HANSEN, P.D.; MARKERT, M.; MUNK, R.; SCHOLZ, N. \& ter HÖFTE, B.B., 1991. Effect of 3,4-dichloroaniline on the early life stages of the zebrafish (Brachydanio rerio): results of a comparative laboratory study. Ecotox.Envir.Safety, 21: 157-164.

NORBERG, T.J. \& MOUNT, D.I., 1985. A new fathead minnow (Pimephales promelas) subchronic toxicity test. Envir.Toxicol. Chem. 4 : 711-718.

NORBERG-KING, T.J., 1989. An evaluation of the fathead minnow seven-day subchronic test for estimating chronic toxicity. Envir. Toxicol.Chem. 8 : 1075-1089.

NORBERG-KING, T.J., 1993. A linear interpolation method for sublethal toxicity: the inhibition concentration (ICp) approach. Version 2.0. (software). US.EPA-Duluth (MN).

NORBERG-KING, T.J.; MOUNT, D.I.; AMATO, J.R.; JENSEN, D.A. \& THOMPSON, J.A., 1991. Toxicity identification evaluation: characterization of chronically toxic effluents. Phase I. National Effluent Toxicity Asses. Center, USEPA/ Duluth. Technical Report 05-91, EPA/600/6-91/005. p.i.

OECD (Organisation for Economic Cooperation and Development), 1998. Fish, short-term toxicity test on embryo and sac-fry stages. OECD Guideline for testing of chemicals - 212. September. $20 \mathrm{p}$.

PICKERING, Q.H., 1980. Chronic toxicity of hexavalent chromium to the fathead minnow (Pimephales promelas). Arch.Environ. Contam.Toxicol. 9: $405-413$.

SLOOFF, W.; VanOERS, A.M. \& ZWART, D., 1986. Margins of uncertainty in ecotoxicological hazard assessment. Environ. Toxicol.Chem. 5 : 841-852.

SNARSKI, V.M. \& OLSON, G.F., 1982. Chronic toxicity and bioaccumulation of mercuric chloride in the fathead minnow (Pimephales promelas). Aquatic Toxicol. 2: 143-156.

USEPA (U.S. Environmental Protection Agency), 1986. Ambient water quality criteria for nickel. EPA 440/5-86-004. 93 p.

VanLEEUWEN, C.J.; ADEMA, D.M.M. \& HERMENS, J., 1990. Quantitative structure-activicy relationship for fish early life stage toxicity. Aquatic Toxicology, 16:321-334.

WALLER, W.T.; AMMANN, L.P.; BIRGE, W.J.; DICKSON, K.L.; DORN, P.B.; LEBLANC, N.E.; MOUNT, D.I.; PARKHURST, B.R.; PRESTON. H.R.; SCHIMMEL, S.C.; SPACIE, E.; \& THURSBY, G.B. 1996. Predicting instream effects from wet tests. In: Grothe, D. R.; Dickson, K. L; Reed-Judkins, D. K. (Eds). Whole effluent toxicity testing: An evaluation of methods and prediction of receiving system impacts. Pensacola (FL). SETAC Press. Chapter 9. 346 p. 
